\title{
Effect of Chemical Composition on the Microstructure and Tribological Properties of Sn-Based Alloys
}

\author{
B. Leszczyńska-Madej iD, M. Madej, and J. Hrabia-Wiśnios
}

(Submitted November 14, 2018; in revised form May 24, 2019; published online June 26, 2019)

\begin{abstract}
This article presents the test results of two bearing alloys on a tin matrix, differing in the content of alloy additions. Microscopic tests were performed using scanning electron microscopy, along with Brinell hardness tests and tests of tribological properties in the conditions of technical dry friction and wet friction using a TU-32 oil. Additionally, wear mechanisms were analyzed depending on the process conditions. The results indicate better tribological properties of the $\mathrm{B82}$ alloy, with a higher content of antimony compared to the $\mathbf{B 8 9}$ alloy. This alloy contains more precipitates of hard phase $\beta-\mathrm{SnSb}$, which both influence the level of the mechanical properties and determine the tribological properties. Additionally, it was proven that using the TU-32 oil as a lubricant practically eliminates adhesive wear, and the post-friction surfaces for both alloys are of a similar nature.
\end{abstract}

Keywords microstructure, tin-based alloys, tribological properties, wear mechanisms

\section{Introduction}

Tin babbitts are classified as casting alloy. The microstructure of these alloys is multiphase, usually three-phase: $\alpha, \beta, \eta$ or $\beta, \varepsilon$, where $\alpha$-solution of antimony and copper in tin, constitutes a soft and ductile matrix, $\beta$-irregular crystals of compound $\mathrm{SnSb}, \eta$-acicular precipitates of compound $\mathrm{Cu}_{6} \mathrm{Sn}_{5}$ (Ref 1-4). The presence of the $\beta$ phase particles increases the hardness of the alloy without deteriorating the sliding properties, but only up to $20 \%$ by weight $\mathrm{Sb}$, further increase in the antimony content in the alloy increases the intensity of wear (Ref 5). Uniform arrangement and the breakup of hard $\beta$-phase particles in the soft matrix harden the alloy and improves its resistance to wear (Ref 6, 7).

Bearings made of tin babbitts work in a turbine in the conditions of fluid friction. During operation of each bearing, friction forces appear, counteracting rotation and causing the release of heat. In order to reduce these forces and carry off the heat, a lubricating film is required between the bearing and the shaft neck. The phenomenon of abrasion is the strongest during stopping and start-up, when the bearing operates in conditions of semi-fluid friction. In this scope, the load capacity of the lubricant layer is not always sufficient to completely separate the sliding, mating elements. Without the lubricating film, a

B. Leszczyńska-Madej and J. Hrabia-Wiśnios, Department of Materials Science and Non-Ferrous Metals Engineering, Faculty of Non-Ferrous Metals, AGH University of Science and Technology, Mickiewicza 30 Av., 30059 Kraków, Poland; and M. Madej, Department of Physical and Powder Metallurgy, Faculty of Metals Engineering and Industrial Computer Science, AGH University of Science and Technology, Mickiewicza 30 Av., 30059 Kraków, Poland. Contact e-mails: bleszcz@agh.edu,plmmadej@agh.edu, and plhrabia@agh.edu.pl.

direct contact between the elements causes dry friction, leading to abrasive wear of the bearing.

Wear resistance and low friction coefficient are some of the most important properties required from slide bearings, as one of the main mechanisms of their wear is the abrasive wear related to sliding friction on the contact surface between the neck and the bushing. Alloys on the tin matrix are among those most commonly used as bearing materials, due to their good resistance to abrasive wear ( $\operatorname{Ref} 8$ ). These alloys are usually used to cast the bushings of full bearings and multilayer bearings cast on steel, cast iron or bronze. Slide bearings are still irreplaceable in many branches of industry, e.g., automotive, railway or shipbuilding, where rolling bearings do not perform well (Ref 9, 10).

The effect of chemical composition and working conditions of bearing alloys was studied by many researchers. Barykin et al. (Ref 1) performed their study on babbitt alloy (4.9 wt.\% $\mathrm{Cu}, 11.3$ wt.\% $\mathrm{Sb}$, remainder $\mathrm{Sn}$ ) in cast state, after the deformation heat treatment, as well as in plasma-sprayed form both at dry friction sliding and using a turbine oil as a lubricant. Tribology tests were performed under the following conditions: sliding speed of $0.79 \mathrm{~m} / \mathrm{s}$, pressure from 0.5 to $3.5 \mathrm{MPa}$ and sliding distance up to $25 \mathrm{~km}$. The obtained results have indicated that the wear at dry sliding of babbitt obtained by plasma spraying was less than that of babbitt in the as-cast state and after a deformation heat treatment. Ishihara et al. (Ref 5) presented the results of effect of amount antimony ranging from 5 to $23 \%$ on sliding wear resistance of white metal. The tests were carried out at rotational speed of $287 \mathrm{rpm}$ in the fluid friction. The results showed that the sliding wear resistance is not affected by the amount of antimony within the range 5$18 \%$; however, the resistance is lowered at the higher amount of antimony. Leszczyńska-Madej et al. (Ref 7) studied the effect of heat treatment on tribological properties of the tin babbitt with $1.5 \% \mathrm{~Pb}$ addition. The specimens were annealed at $150{ }^{\circ} \mathrm{C}$ for $2,8,24$ and $48 \mathrm{~h}$. The wear tests were carried out using block-on ring tester operating under dry and wet conditions with a rotating speed of $136 \mathrm{r} / \mathrm{min}$ unchanged during the entire test and the load of $67 \mathrm{~N}$. The results show that the most favorable combination of the properties was obtained in the alloy annealed for $48 \mathrm{~h}$. In Ref 11, Leszczyńska-Madej et al. 
presented the results of tribological tests of babbitt bushes in steam turbine sliding bearings. They observed that the babbitt bearing shows higher loss of mass than the as-cast babbitt. Bora et al. (Ref 12) performed their study on two different tinbased bearing materials (WM-2 and WM-5) using scratch and Martens hardness techniques. The scratch velocity was in the range of $15-90 \mathrm{~mm} / \mathrm{min}$, and the applied loads was $5-20 \mathrm{~N}$. The obtained results have indicated that the friction coefficient is more sensitive to normal loads compared to scratch velocities. Goudarzi et al. (Ref 13) studied the effect of solidification rate and heating on microstructure and properties tin-based white metal. The wear tests were carried out using pin-on-disk tester with a sliding speed: 150, 200 and $250 \mathrm{rpm}$ and the loads 7, 14 and $28 \mathrm{~N}$ in the condition of dry friction. Authors concluded that the alloy with lower content of $\mathrm{Sb}$ and $\mathrm{Cu}$ has more resistance to wear under the same conditions and also that decrease in both applied load and rotating speed shifts the transitional sliding distance to further distances. Zeren (Ref 14, 15) also investigated the tribological behavior of two different tin-based bearing materials (with 7\% Sb and $20 \% \mathrm{Sn}$ ) in dry sliding conditions. The results show that the wear with respect to sliding distance is lower in alloy with higher $\mathrm{Sb}$ content.

The article presents the results of research on materials currently used in industry and attempts to classify them according to wear resistance. The possibility of improving the properties is described for example in patent PL 216877 B1 (Ref 16). The tests were carried out in conditions of continuous friction with parameters similar to industrial conditions and simulating work with starting and running conditions of the bearing bushing (start-stop method). Analyzing the literature, no such combination of tests was found; therefore, such an approach to research seems to be necessary from the point of view of this type of bearing work.

Studies of tribological properties were done under conditions different than those presented in the literature by other authors in earlier works. The results of these methods are difficult to compare due to the different nature of tribological contact (e.g., change in the friction surface) and tribological test. Additionally, one fact should be stressed namely that the reference literature gives no results of testing the tribological

Table 1 Chemical composition of investigated alloys, wt. $\%$

\begin{tabular}{|c|c|c|c|c|c|c|}
\hline \multicolumn{2}{|c|}{ Alloy name } & \multicolumn{5}{|c|}{ Chemical composition, wt.\% } \\
\hline Grade mark & Designation & Sn & $\mathbf{P b}$ & Sb & $\mathbf{C u}$ & As \\
\hline $\mathrm{SnSb} 12 \mathrm{Cu} 6 \mathrm{~Pb}$ & B82 & Residue & $1 \div 3$ & $11 \div 13$ & $5 \div 7$ & 0.1 \\
\hline $\mathrm{SnSb} 9 \mathrm{Cu} 4$ & B89 & Residue & 0.35 & $7 \div 8$ & $3 \div 4$ & 0.1 \\
\hline
\end{tabular}

properties of these alloys under the conditions of intermittent (start-stop) friction.

The results presented herein provide information about the wear mechanisms depending on the chemical composition and working conditions of the thin babbitts. Due to different chemical composition, the investigated alloys have different microstructure and properties, which has a direct impact on the tribological properties of these materials.

\section{Materials and Methods}

The tests concerned two tin-based casting alloys: $\mathrm{SnSb} 9 \mathrm{Cu} 4$ (B89) and $\mathrm{SnSb} 12 \mathrm{Cu} 6 \mathrm{~Pb}$ (B82). The alloys were cast into cast iron chills and then cooled in ambient air. Table 1 presents the chemical composition of the tested alloys.

The microstructure of the samples was investigated using scanning electron microscopy, along with an analysis of the chemical composition in the micro-areas (microscope Hitachi SU 70). Also, the phase composition was tested using $\mathrm{x}$-ray diffractometer (BRUKER) with cobalt lamp Co $\mathrm{K} \alpha=1.79 \AA$.

Hardness was tested using the Brinell method, with an Innovatest hardness tester; the test involved a sintered carbides ball, $2.5 \mathrm{~mm}$ in diameter, and a load of $31.25 \mathrm{~kg}$. The average hardness values and standard deviations were determined.

The abrasive wear resistance of the bearing alloys was tested using a T-05 roller-block tester. The measurement was taken in ambient temperature, with translational motion in dry and fluid sliding contact, using TU-32 oil. In order to verify the behavior of the investigated alloys in conditions simulating multiple start-ups and multiple stoppings of a turbine, a "start-stop" test on a sliding distance of $10,000 \mathrm{~m}$ was performed. This test consisted in consecutive 10 cycles of friction $1000 \mathrm{~m}$ each with the TU-32 oil as a lubricant having kinematic viscosity $32.7 \mathrm{~mm}^{2} / \mathrm{s}$ at $40{ }^{\circ} \mathrm{C}$. The oil specification TU-32 is in accordance with DIN 51515 part 1, ISO 8068. Table 2 presents the applied parameters of the friction process. Minimum three tribological tests were performed for each variant of the material tested. The applied tester enables performance of tests in accordance with the methods specified in standards ASTM: D 2714, D 3704, D 2981 and G 77.

Tests were carried out according to some guidelines comprised in ASTM D 3704, which means that a countersample with a hardness recommended by the standard (H 60) was used. To make the test better adapted to the real conditions of babbitt operation, it was necessary to change the oscillating motion to rotary motion (as permitted under related standards) and reduce the load by half to meet the actual loading conditions of shafts in heat and power plants and characteristics of the babbitt itself. The load of $50 \mathrm{~N}$ (a variable in time due to changes in the contact surface) was selected, which allowed

Table 2 The wear test parameters

\begin{tabular}{|c|c|c|c|c|}
\hline Sliding contact & Counter-specimen & Rotational speed & Load & Sliding distance \\
\hline $\begin{array}{l}\text { Technical dry } \\
\text { Fluid } \\
\text { Fluid }\end{array}$ & $\phi 49.5 \mathrm{~mm}$, steel $100 \mathrm{Cr} 6$, heat-treated, with hardness $55 \mathrm{HRC}$ & $136 \mathrm{rpm}$ & $50 \mathrm{~N}$ & $\begin{array}{l}100,1000 \mathrm{~m} \\
1000 \mathrm{~m}, 10,000 \mathrm{~m} \\
10 \text { cycles } \times 1000 \mathrm{~m}\end{array}$ \\
\hline
\end{tabular}


carrying out tests comparable in terms of technical dry and wet friction $(1000 \mathrm{~m})$.

During the tribological test, the friction force $F$ (required to determine the friction coefficient) was recorded constantly, and the weight loss was calculated based on the weight difference before and after the process. After the tests, the sample surfaces obtained in the tribological contact were observed using a scanning electron microscope.

\section{Results and Discussion}

\subsection{Microstructure and Phase Analysis}

Select photographs of the microstructure of tin-based casting bearing alloys made using a scanning electron microscope are shown in Fig. 1, 2 and 3. The investigated alloys are characterized by multiphase microstructure, consisting of large hard precipitates of the $\mathrm{SnSb}$ phases and numerous precipitates of the CuSn phases, both needle shaped and nearly globular shaped. The matrix is a solution of antimony and copper in tin (Ref 6, 8).

Lead in the alloys is arranged uniformly and visible in the photographs of the microstructure as bright, dispersion precipitates, located mostly inside the tin-rich matrix grains. Additionally, the presence of larger clusters of lead was found on the boundaries of the grains, which is particularly visible in the B82 alloy (Fig. 1, 2 and 3), which contains more $\mathrm{Pb}$. This results from the presence of lead in this alloy (up to 3\%), while the maximum lead content in tin is $1.3 \%$. The results of an $\mathrm{x}-$ ray phase analysis shown in Fig. 4 confirmed the proper structure of the investigated alloys; they also prove that the

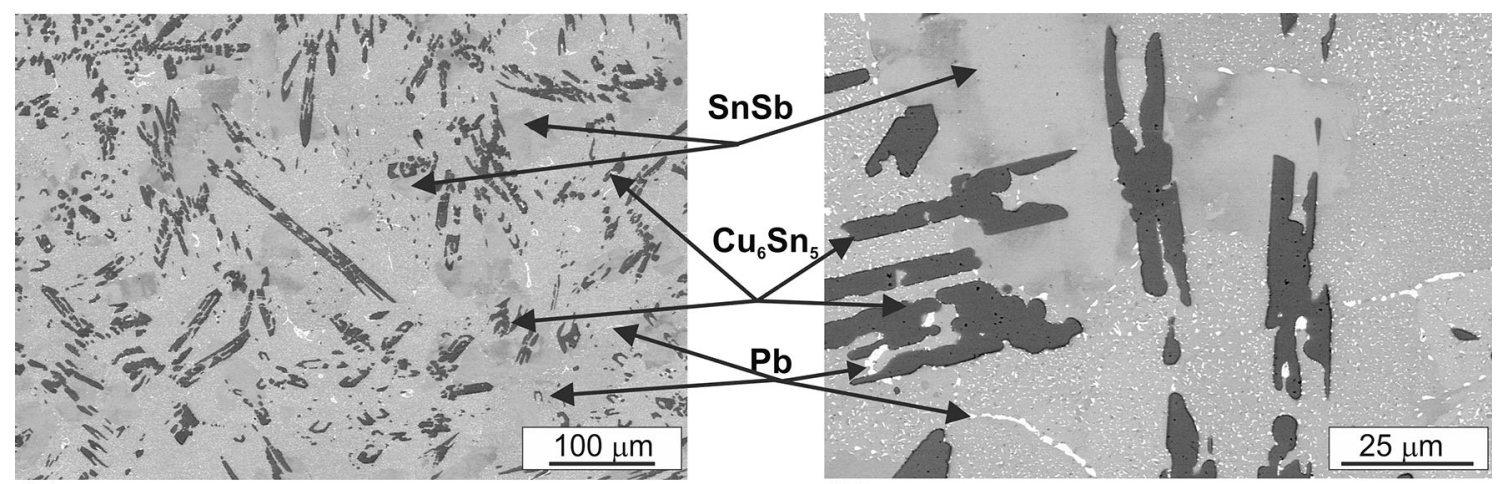

(a)

(b)

Fig. 1 Microstructure of the B82 alloy; (a) magnification 200×, (b) magnification $1000 \times$; SEM
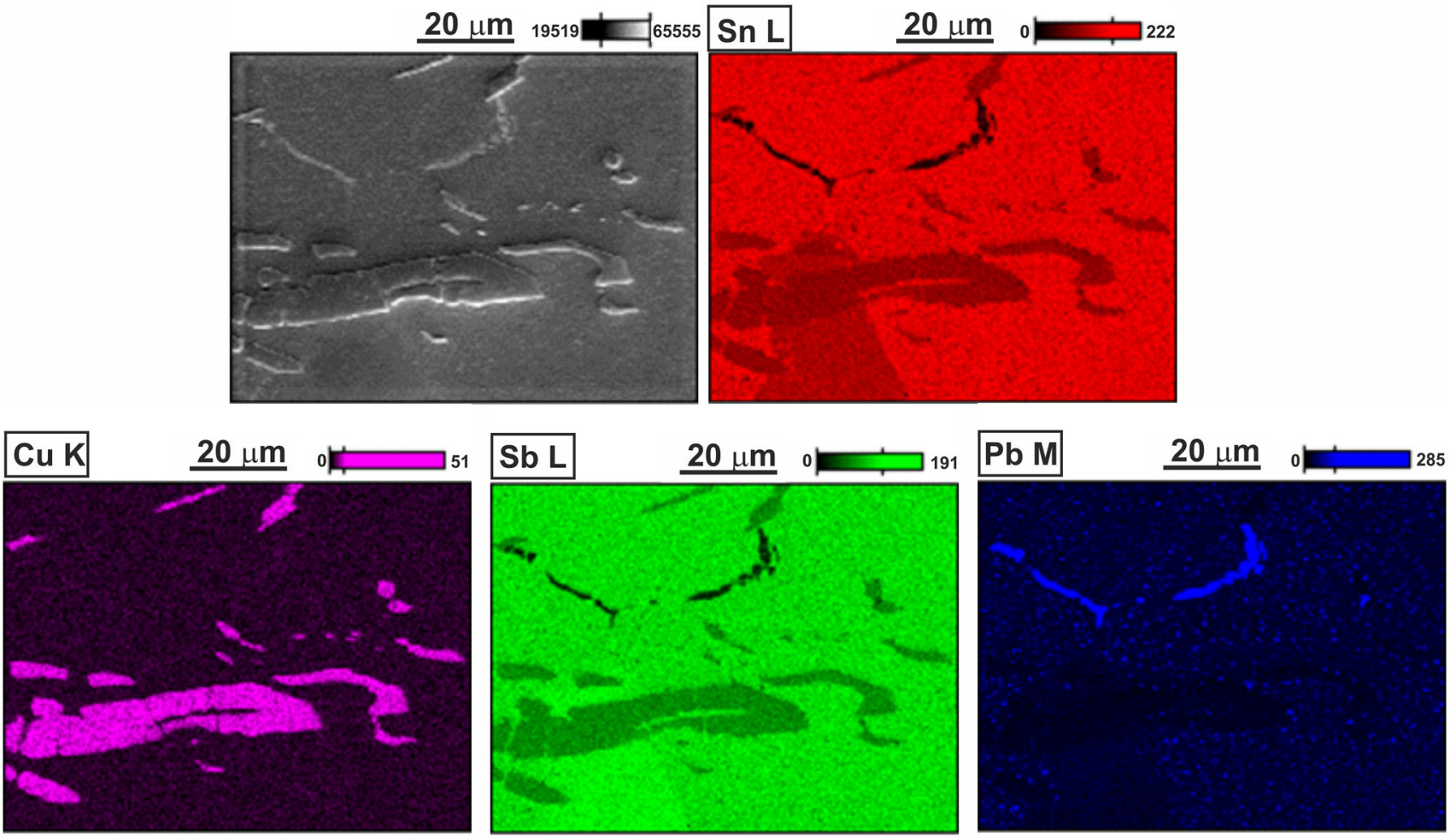

Fig. 2 Microstructure and distribution maps of $\mathrm{Sn}, \mathrm{Cu}, \mathrm{Sb}$ and $\mathrm{Pb}$ in the $\mathrm{B} 82$ alloy 


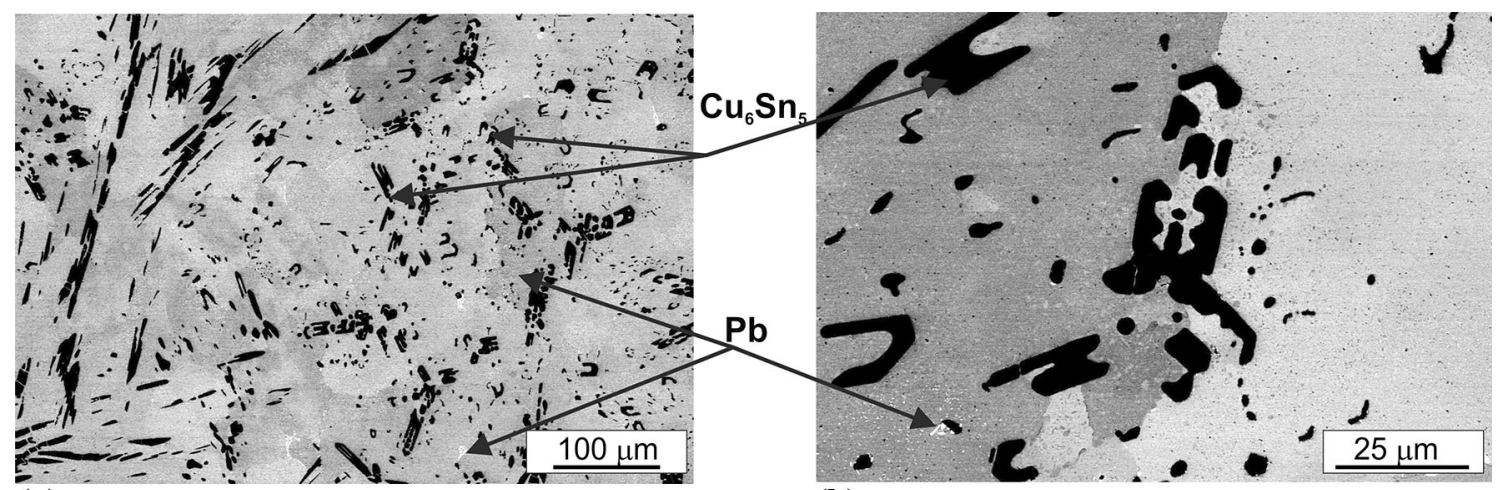

(a)

(b)

Fig. 3 Microstructure of the B89 alloy; (a) magnification $200 \times$, (b) magnification $1000 \times$; SEM

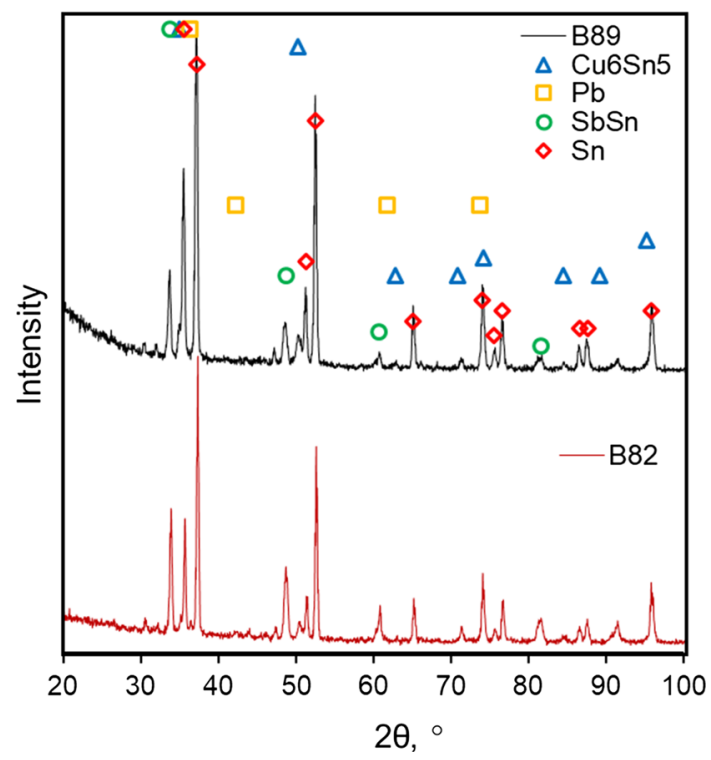

Fig. 4 Results of x-ray phase analysis of the investigated alloys

peak coming from the $\mathrm{SnSb}$ phase is clearer for alloy B82 (Fig. 4), which indicates a higher content of this phase in the alloy. Lower content of antimony, as well as other additives in alloy B89, directly influences the hardness, as well as tribological properties of this alloy.

The hardness measurement showed significant differences in the hardness of the investigated alloys. The hardness values are $20 \mathrm{HB}$ for the B89 alloy and $27 \mathrm{HB}$ for the B82 alloy, respectively. A higher hardness of the B82 alloy along with a higher range of standard deviation is caused mostly by the presence of large, hard phases of the SnSb compound in the microstructure of the investigated alloy. The measured microhardness of this phase is $74 \mathrm{HV} 0.01$, respectively.

\subsection{Tribological Properties}

Below are the results of the tribological properties of the investigated alloys. The tests were carried out on two bearing alloys based on tin, differing in the content of alloy additives, and mainly in the content of $\mathrm{Sb}$ and $\mathrm{Pb}$. Differences in the content of alloying elements have a significant impact on the tribological characteristics of these materials and on their wear behavior, first of all.

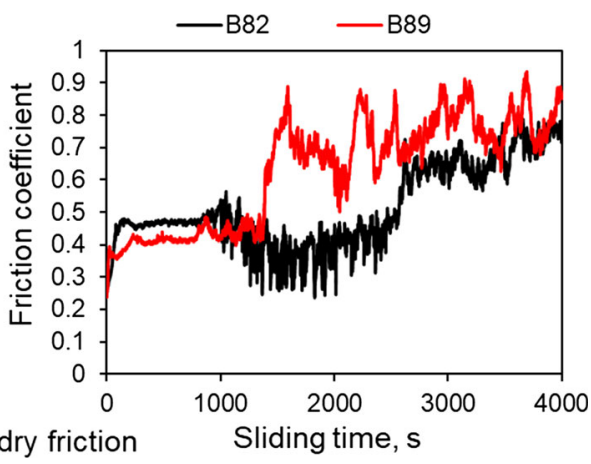

Fig. 5 Coefficient of friction of bearing alloys as a function of time; dry sliding condition

Three different process variants were used in the tests, i.e., technical dry friction, wet friction and start-stop friction aimed at simulating the starting and running conditions of the bearing bushing. In the case of technical dry friction, two friction paths were used, i.e., 100 and $1000 \mathrm{~m}$, and in the case of wet friction, the friction path of 1000 and $10,000 \mathrm{~m}$, the last variant included 10 cycles of $1000 \mathrm{~m}$ each. In each of the variants, the same load was applied, i.e., $50 \mathrm{~N}$. Studies of tribological properties were done under conditions different than those presented in the literature by other authors in earlier works. The results of these methods are difficult to compare due to the different nature of tribological contact (e.g., change in the friction surface). Figure 5 presents diagram, showing changes to the friction coefficient as a function of the process time in the conditions of technical dry fiction.

During technical dry friction, at the initial stage of the process (up to about $200 \mathrm{~m}$ ) the curves illustrating the friction coefficient are similar, and there are no major changes to the friction coefficient (Fig. 5). For the B89 alloy, the friction coefficient is, on average, about $\mu=0.4$, while for alloy B 82 it is higher and comes to about $\mu=0.48$ on average. Such a long, stable friction course may be beneficial from the perspective of a potential turbine malfunction, caused by momentary loss of lubrication.

As the sliding distance expends, the nature of the curves illustrating the course of changes to the friction coefficient for both the investigated alloys changes. The friction coefficient for alloy B89 increases continuously up to a certain value, which is accompanied by significant fluctuation; in turn, the friction 


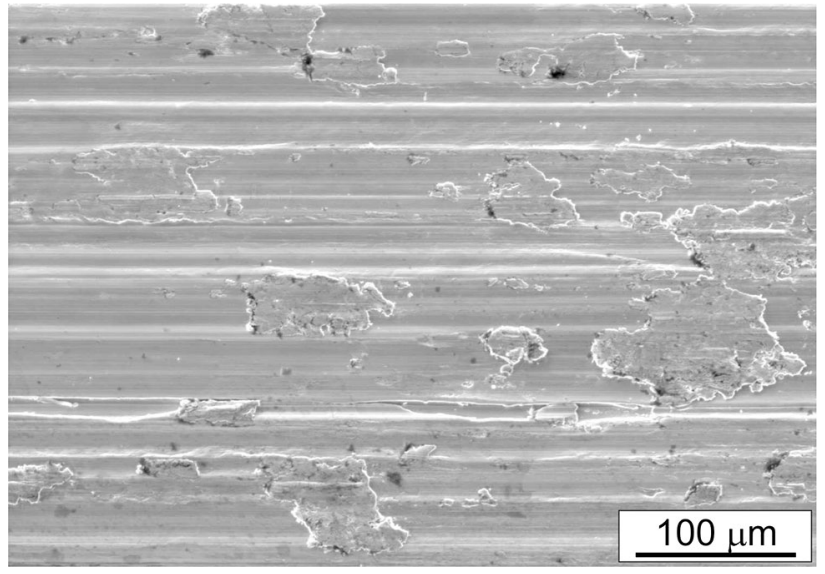

Fig. 6 Characteristic sample surface of the B82 alloy after tribological tests in dry conditions; mag. 500×, sliding distance $100 \mathrm{~m}$; SEM

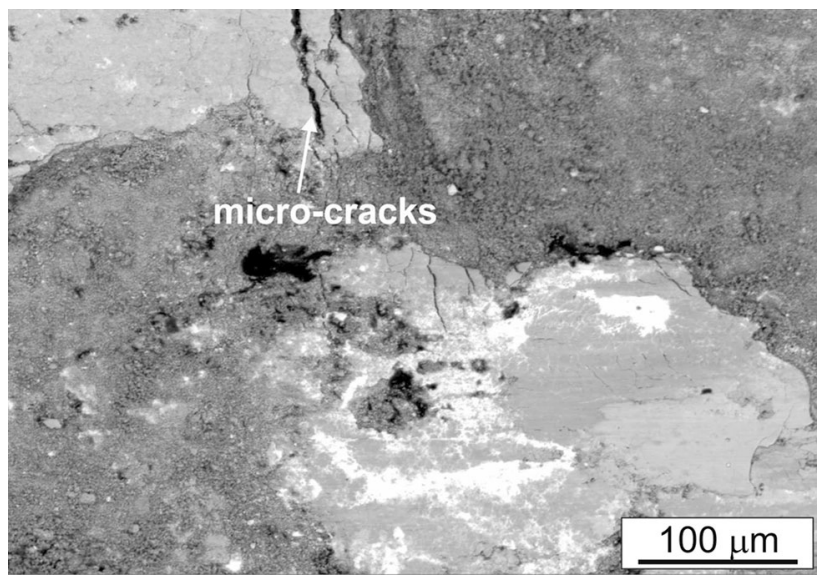

Fig. 7 Characteristic sample surface of the B82 alloy after tribological tests in dry conditions; mag. $500 \times$, sliding distance $1000 \mathrm{~m}$; SEM coefficient for alloy B82 initially decreases and then grows continuously. Fluctuations of the curve illustrating the changes to the friction coefficient are lower than in the case of the B89 alloy (Fig. 5). Lower values of the friction coefficient for the B82 alloy can be explained by a decrease or loss of adhesion, arising from the presence of hard particles of the $\mathrm{SnSb}$ and $\mathrm{CuSn}$ phases (particularly the $\mathrm{SnSb}$ phase, which is more abundant in the B82 alloy than in B89) at the friction center, reducing the effective contact surface between the soft matrix and the counter-specimen material. The post-friction surface morphology is similar for both alloys, and the major wear mechanism is adhesive wear combined with ridging and scratching. There is also a locally visible movement of the plastic matrix, in the direction of the friction process (Fig. 6 and 7).

Variations of the friction coefficient during the tribological test arise from an increased role of the adhesive wear, which is the dominating wear mechanism during technical dry friction. After friction, there are also visible surface cracks, located transversely to the friction direction, which indicates the presence of fatigue wear in the friction process. Local movements of the plastic matrix were also observed (Fig. 7). The post-friction surface element distribution maps shown in Fig. 8 indicate the presence of oxidation, particularly in the areas where copper and lead occur. Apart from the included oxide areas, one can also observe minute, singular oxide particles, which probably broke off the compact layers and may act as an abradant during friction. Additionally, the presence of iron indicates the transfer of material from the counterspecimen matrix to the surface of the investigated material.

Figure 9 presents diagram showing changes to the friction coefficient as a function of the process time in the conditions of wet friction with TU-32 oil. The wet friction conditions were also applied in a start-stop test, intended to simulate the actual conditions of multiple start-ups and stops of a turbine.

The presence of oil and its circulation during continuous wet work helps remove the wear products, which would otherwise increase wear at the friction center. Stopping and restarting of the turbine cause the presence of wear product at the friction
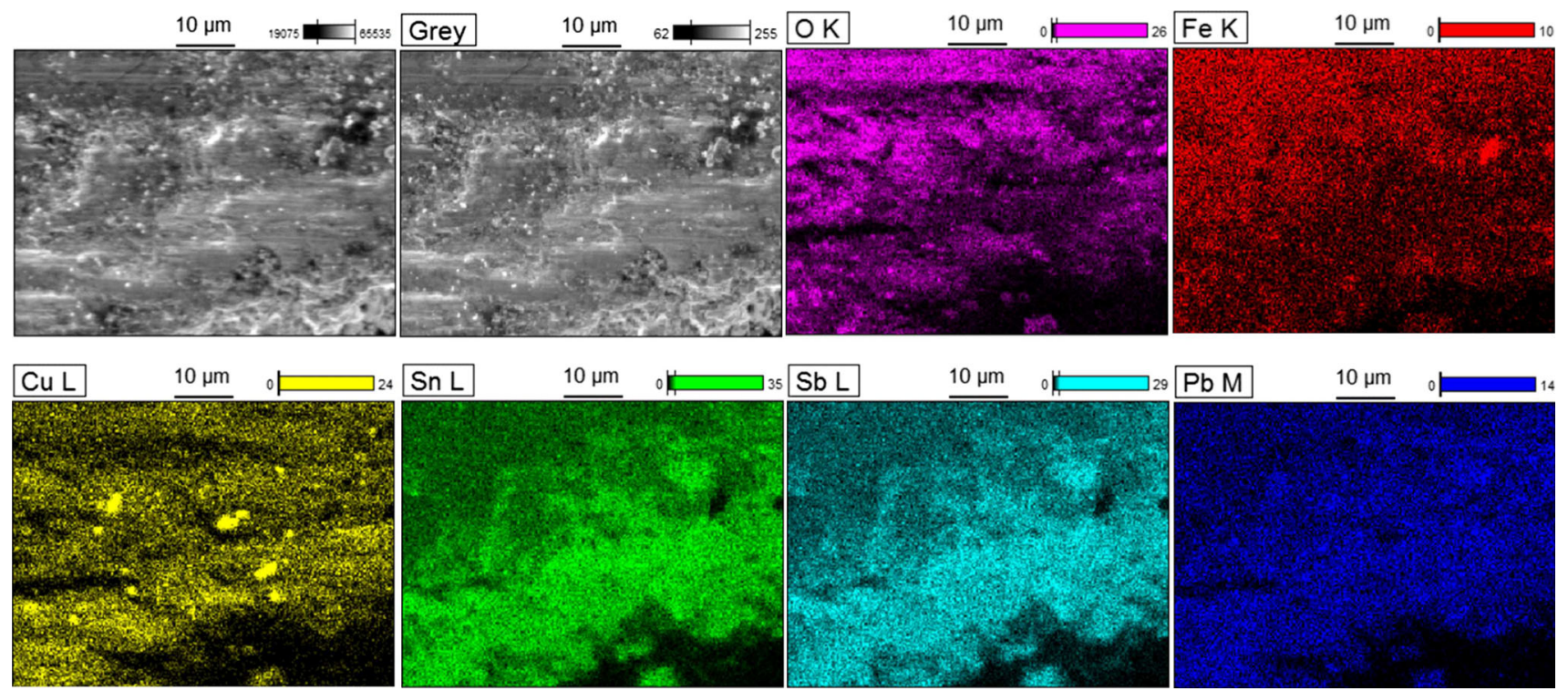

Fig. 8 Characteristic sample surface of the B89 alloy after tribological tests in dry conditions (1000 m) and maps of the $\mathrm{O}, \mathrm{Fe}, \mathrm{Pb}, \mathrm{Cu}, \mathrm{Sn}$ and $\mathrm{Sb}$ elements; SEM 
center for a certain period of time, which alters the wear mechanisms. Additionally, start-up and stoppage of the turbine increase the temperature at the center, which can shorten the life of such bearing.

Use of the TU 32 oil, apart from distinctly reducing the friction coefficient, stabilizes the course of friction. The friction coefficient curves are free of the fluctuations typical of technical dry friction. In the B82 alloy with higher contents of $\mathrm{Pb}$ and $\mathrm{Sb}$, stabilization of the friction course is much slower than in the B89 alloy (Fig. 9a and b). This phenomenon can be explained by a greater role of the matrix in the friction process; at the initial stage of friction, surface irregularities are removed, and stabilization occurs only after this stage. The friction coefficient for the B82 alloy is two times lower than for the B89
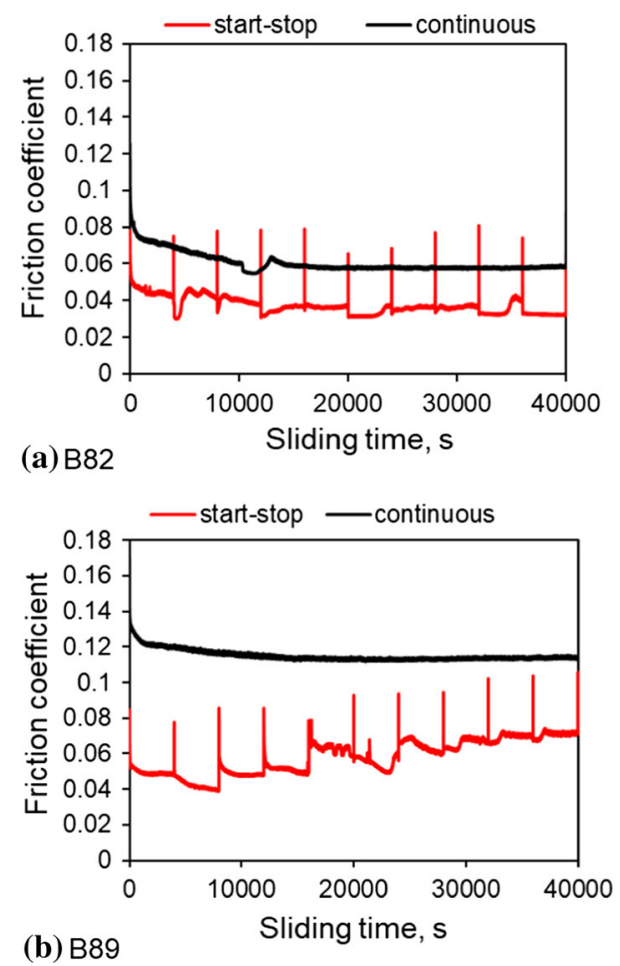

Fig. 9 Coefficient of friction of bearing alloys as a function of time; wet sliding condition; (a) B82 alloy, (b) B89 alloy alloy, which can be explained by a greater number of precipitates of the hard $\mathrm{SnSb}$ phase.

In the case of the start-stop process, diagrams illustrating changes to the friction coefficient include peaks, which correspond to the stopping and start-up of the process (Fig. 9a and b). Each stopping and resumption of the process causes about a twofold increase in the friction coefficient, which then stabilizes at about 0.04 for the B82 alloy and 0.058 for the B89 alloy. For the B82 alloy, the friction coefficient remains constant, whereas for the B89 alloy it grows monotonically, yet this coefficient stays low and beneficial for this type of materials. The data above indicate that the B82 alloy can work longer even in variable working conditions.

The nature of wear for bearing alloys is determined by the cooperation between the soft matrix and hard precipitates of inter-metallic phases. After friction while using the TU-32 oil, the surfaces of both alloys are similar (Fig. 10 and 11).

Use of the TU-32 oil allows to eliminate adhesive wear (Fig. 10a and 11a), which helps both decrease the friction coefficient and reduce weight loss during alloy operation, while expanding its work significantly. There are visible, local chippings of hard phases; the dominant wear mechanism is scratching. Additionally, in the case of the start-stop process, the recurring start-up and stoppage enhance the effect of plastic deformation, which in this case causes more intensive movement of the reinforcing phase particles (Fig. 10b and 11b).

The presence of potential scratching on the surfaces after friction is determined by hard phase particles present in the oil, which are transferred there after breaking out of the plastic matrix (Ref 1). Bushings are particularly exposed to this phenomenon during start-up and stopping.

The maps of surface element distribution after wet friction presented in Fig. 12 confirm the presence of oxidation in the friction process. Just like in the case of technical dry friction, oxidation occurs on the precipitates of $\mathrm{Pb}$ and $\mathrm{Cu}$.

Changes to the friction coefficient are reflected in its determined, average values. During wet friction, the B82 alloy is characterized by over two times lower friction coefficient than the B89 alloy (Fig. 13a). The determined values of the friction coefficient for the wet process, irrespective of the sliding distance, are 0.045 for the B82 alloy and 0.1 for the $\mathrm{B} 89$, respectively. In the case of the start-stop process, the average friction coefficient determined for the B82 alloy is 0.037, whereas for B $89-0.058$

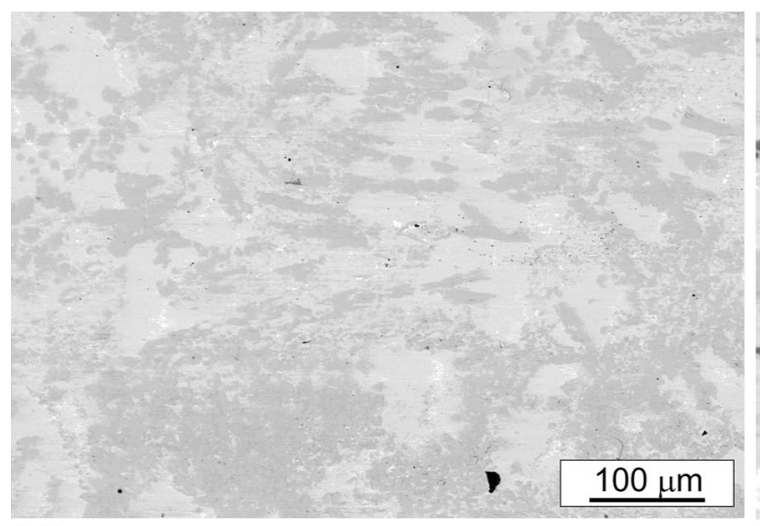

(a)

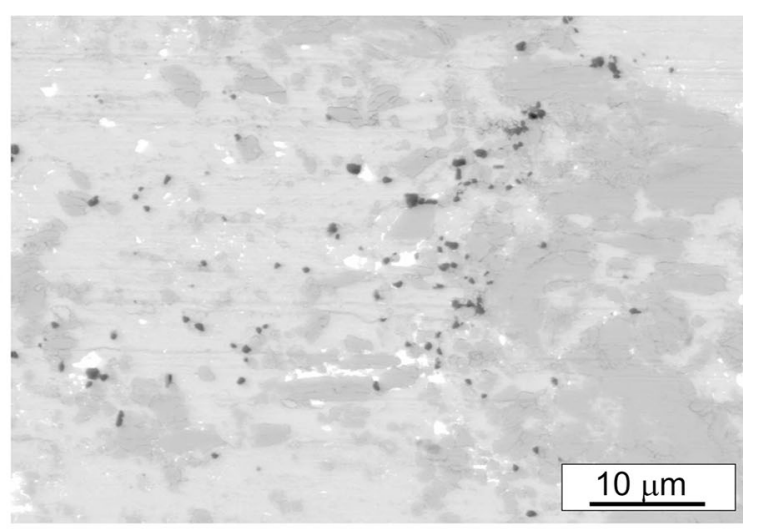

(b)

Fig. 10 Characteristic sample surface of the B82 alloy after tribological tests in wet conditions; (a) sliding distance 10,000 m, (b) start-stop; sliding distance $10,000 \mathrm{~m}$; SEM 


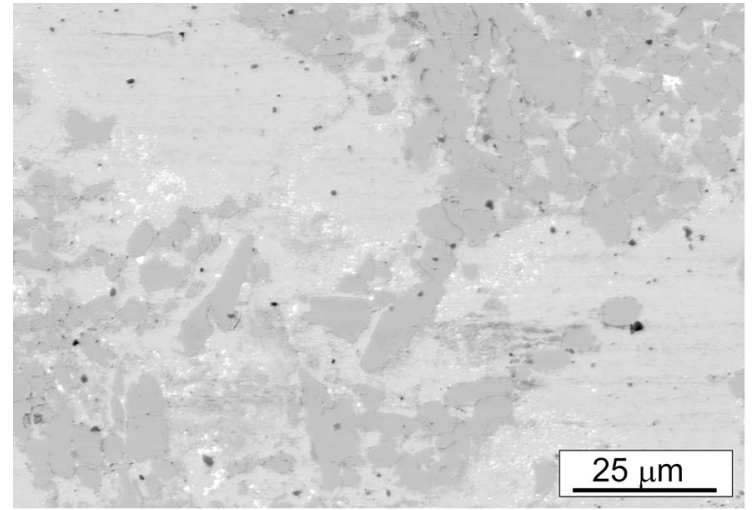

(a)

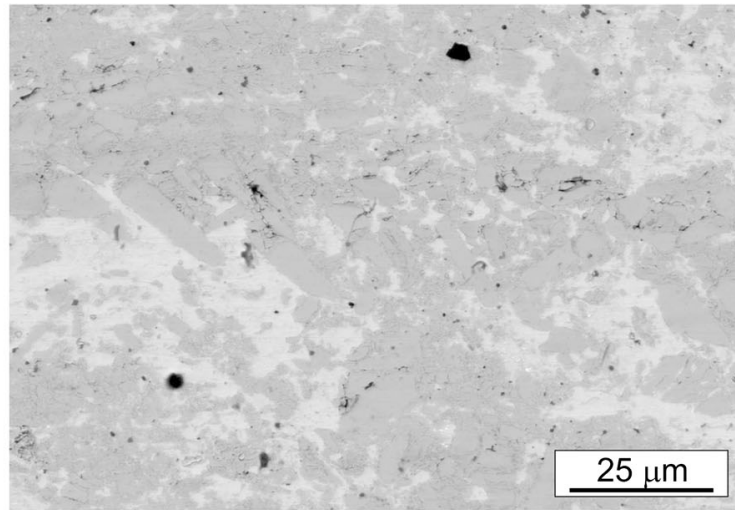

(b)

Fig. 11 Characteristic sample surface of the B89 alloy after tribological tests in wet conditions; (a) sliding distance 10,000 m, (b) start-stop; sliding distance $10,000 \mathrm{~m}$; SEM
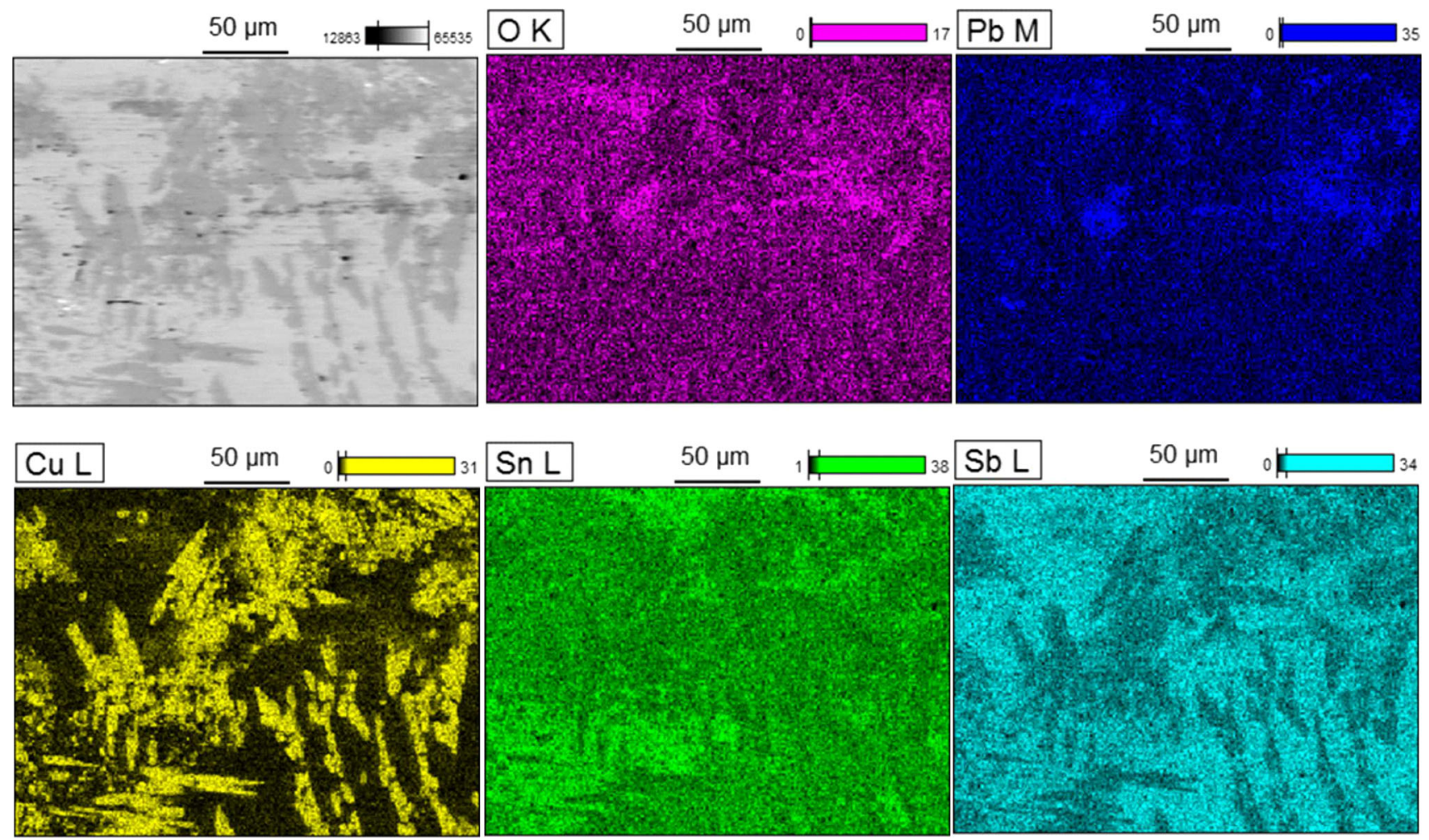

Fig. 12 Characteristic sample surface of the $\mathrm{B} 82$ alloy after tribological tests in wet conditions $(10000 \mathrm{~m})$ and maps of the $\mathrm{O}, \mathrm{Pb}, \mathrm{Cu}, \mathrm{Sn}$ and $\mathrm{Sb}$ elements; SEM

For technical dry friction, the determined values of friction coefficient are much higher and comparable for both alloys. They come to about 0.35 for friction on sliding distance $100 \mathrm{~m}$ and 0.5 for friction on sliding distance $1000 \mathrm{~m}$ (Fig. 13b).

Lengthening of the sliding distance is related to the change of the friction surface with the process time, which increases the average friction coefficient - this is a quality typical of the applied device. Use of the TU-32 oil as a lubricant has a positive impact on the friction course, significantly reducing the friction coefficient and reducing wear. During start-up of the bearing, technical dry friction occurs, and oil reaches the friction center only after a certain time, which makes it vital to also analyze phenomena which occur during technical dry friction.

One of the measures of material resistance to abrasive wear when using the T05 tester is weight loss. The weight losses determined for wet and dry friction tests with sliding distances of 1000 and $10,000 \mathrm{~m}$ for both alloys are comparable and, on average, come to $0.028 \%$ for sliding distance $1000 \mathrm{~m}$ and $0.05 \%$ for sliding distance $10,000 \mathrm{~m}$ (Fig. 14a). In the case of 
母1000m $10000 \mathrm{~m}$ 日start-stop 10x1000m

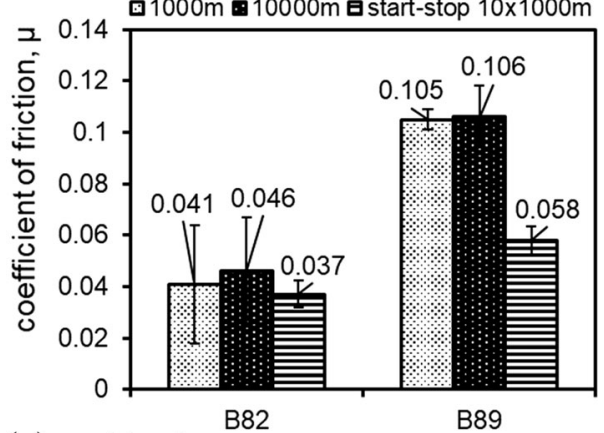

(a) wet test

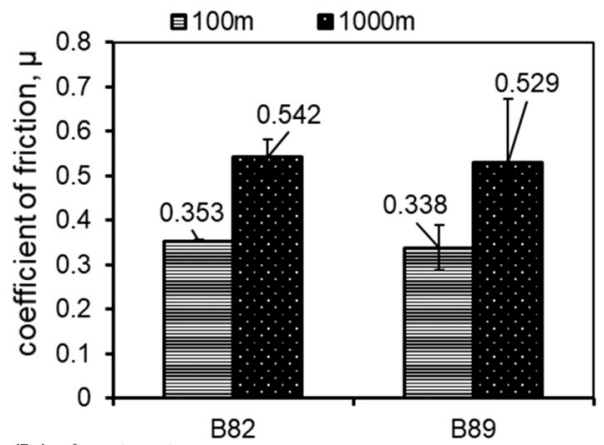

(b) dry test

Fig. 13 Friction coefficient (a) determined for wet friction, (b) determined for technical dry friction

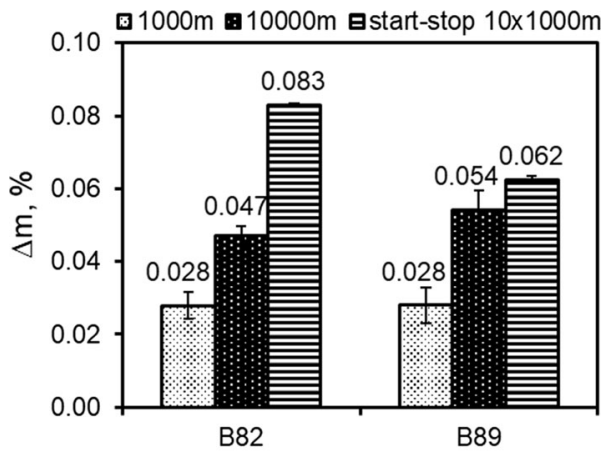

(a) wet test

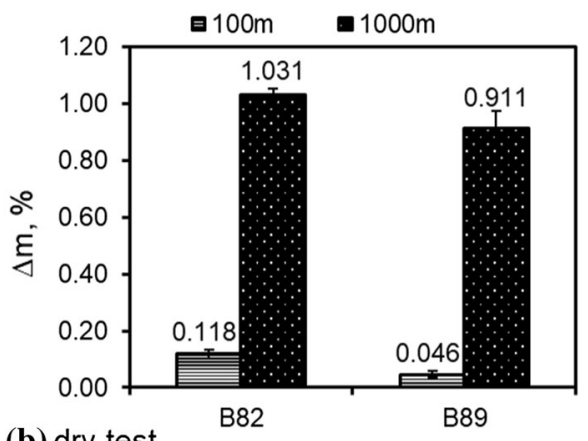

(b) dry test

Fig. 14 Weight loss (a) determined for wet friction, (b) determined for technical dry friction

the start-stop test, the B82 alloy showed greater wear, with loss weight of $0.083 \%$ for the B82 alloy and $0.062 \%$ for the B89 alloy. Greater weight loss for the B82 alloy may be related to a greater number of the $\mathrm{SnSb}$ phase precipitates in this alloy, which cracked during start-up and stopping and could have chipped.

In the case of technical dry friction, the determined weight losses are, as expected, much higher. Samples of the B89 alloy were characterized by slightly lower weight loss, both for sliding distance of 100 and $1000 \mathrm{~m}$ (Fig. 14b). The average values were as follows: for the B82 alloy: $0.118 \%$ for sliding distance $100 \mathrm{~m}$ and $1.031 \%$ for sliding distance $1000 \mathrm{~m}$, whereas for the B89 alloy: $0.046 \%$ for sliding distance $100 \mathrm{~m}$ and $0.911 \%$ for sliding distance $1000 \mathrm{~m}$.

In summary, differences in the content of alloying elements have a significant impact on the tribological characteristics and on wear behavior. Lower addition of $\mathrm{Sb}$ in the B89 alloy increases the coefficient of friction under wet friction conditions, while the weight loss remains at a similar level.

\section{Conclusion}

On the basis of the tests performed, the following conclusions were formulated:

1. The investigated alloys are characterized by multiphase microstructure consisting of precipitates of $\mathrm{SnSb}$ and $\mathrm{CuSn}$ phases, as well as a tin-rich matrix. Lead is arranged uniformly in the matrix, forming local clusters at grain boundary. The content of the $\mathrm{SnSb}$ phase is higher in the B82 alloy, as confirmed by the results of an X-ray phase analysis.

2. The B82 alloy is harder than B89, due to a higher number of the $\mathrm{SnSb}$ phase precipitates. The hardness of the investigated alloys is $27 \mathrm{HB}$ and $20 \mathrm{HB}$ for the $\mathrm{B} 82$ and the B89 alloys, respectively.

3. The B82 alloy shows better tribological properties than the B89 alloy, both during technical dry and wet friction, using the TU-32 oil. Using the TU-32 oil as lubricant significantly reduces the friction coefficient and weight loss of the investigated alloys. The friction coefficient determined for wet friction is 0.045 for the B82 and 0.1 for the B89 alloy. In the case of the start-stop process, the average friction coefficient determined for the B82 alloy is 0.037 , whereas for the B89 alloy it comes to 0.058

4. The major wear mechanism for dry friction is adhesive wear, along with scratching and ridging. Use of the TU32 oil as lubricant practically eliminates adhesive wear, and the dominating wear mechanism is scratching. In the case of both technical dry friction and wet friction, a presence of oxidation in the friction process was found; also, during technical dry friction the counter-specimen matrix material was transferred to the surface of the investigated material, as evidenced by the presence of iron on the surface after friction.

\section{Acknowledgment}

The financial support of the Polish State Committee for Scientific Research under the Grant Number 16.16.180.006 is kindly acknowledged. 


\section{Open Access}

This article is distributed under the terms of the Creative Commons Attribution 4.0 International License (http://creativecommons.org/ licenses/by/4.0/), which permits unrestricted use, distribution, and reproduction in any medium, provided you give appropriate credit to the original author(s) and the source, provide a link to the Creative Commons license, and indicate if changes were made.

\section{References}

1. N.P. Barykin, F.A. Sadykov, and I.R. Aslanyan, Wear and Failure of Babbit Bushes in Steam Turbine Sliding Bearings, J. Mater. Eng. Perform., 2000, 9(1), p 110-115

2. F.A. Sadykov, N.P. Barykin, I. Sh Valeev, and V.N. Danilenko, Influence of the Structural State on Mechanical Behavior of Tin Babbit, J. Mater. Eng. Perform., 2003, 12(1), p 29-36

3. A.K. Valeeva, I.S. Valeev, and R.F. Fazlyakhmetov, On the Wear Rate of an Sn11Sb55Cu Babbitt, J. Frict. Wear, 2017, 38(1), p 53-57

4. A. Harnoy, Bearing Design in Machinery: Engineering Tribology and Lubrication, Marcel Dekker Inc., New York, 2002

5. S. Ishihara, K. Tamura, and T. Goshima, Effect of Amount of Antimony on Sliding Wear Resistance of White Metal, Tribol. Int., 2010, 43, p 935-938

6. M.M. Goudarzi, S.A.J. Jahromi, and A. Nazarboland, Investigation of Characteristics of Tin-Based White Metals as a Bearing Material, Mater. Des., 2009, 30, p 2283-2288

7. B. Leszczyńska-Madej and M. Madej, The Tribological Properties and the Microstructure Investigations of Tin Babbit with $\mathrm{Pb}$
Addition After Heat Treatment, Arch. Metall. Mater., 2016, 61(4), p $1861-1868$

8. G.C. Pratt, Materials for Plain Bearings, Int. Metall. Rev., 1973, 18(2), p $62-88$

9. M.V.S. Babu, A.R. Krishna, and K.N.S. Suman, Review of Journal Bearing Materials and Current Trends, Am. J. Mater. Sci. Technol., 2015, 4(2), p 72-83

10. B. Challen and R. Baranescu (eds.), Diesel Engine Reference Book. Chapter 13-Bearings and Bearings Metals, 2nd edn. (SAE, 1999)

11. B. Leszczyńska-Madej and M. Madej, The Properties of Babbitt Bushes in Steam Turbine Sliding Bearings, Arch. Metall. Mater., 2011, 56(3), p $805-812$

12. M.O. Bora, O. Coban, T. Sinmazcelik, V. Gunay, and M. Zeren, Instrumented Indentation and Scratch Testing Evaluation of Tribological Properties of Tin-Based Bearing Materials, Mater. Des., 2010, 31, p 2707-2715

13. M.M. Goudarzi, S.A. Jenabali Jahromi, and A. Nazarboland, Investigation of Characteristics of Tin-Based White Metals as a bearing Material, Mater. Des., 2009, 3, p 2283-2288

14. A. Zeren, Embeddability Behaviour of Tin-Based Bearing Material in Dry Sliding, Mater. Des., 2007, 28, p 2344-2350

15. A. Zeren, E. Feyzullahoglu, and M. Zeren, A Study on Tribological Behaviour of Tin-Based Bearing Material in Dry Sliding, Mater. Des., 2007, 2007(28), p 318-323

16. M. Madej and B. Leszczyńska-Madej, Sposób obróbki cieplnej babbitów cynowych (Method for Heat Treatment of Tin Babbits). PL 219677 B1 (30.06.2015 WUP 06/15) (in Polish)

Publisher's Note Springer Nature remains neutral with regard to jurisdictional claims in published maps and institutional affiliations. 